\title{
Has the London 2012 Olympic Inspire programme inspired a generation? A realist view
}

\section{Vassil Girginov}

Department of Life Sciences, Brunel University, UK

European Physical Education Review, 2016: 1-16 DOI:

$10.1177 / 1356336 \times 15623169$

\section{Abstract}

The organisers of the 2012 London Olympics have endeavoured explicitly to use the Games to inspire a generation. This is nothing short of putting the main claim of Olympism to the test, but surprisingly the Inspire project has received virtually no scholarly scrutiny. Using an educationally-informed view of inspiration, this paper interrogates the official evaluations of the London 2012 Inspire programme from a realist evaluation perspective and asks what are the theory, mechanisms and outcomes of the programme. It also considers the relationship between evidence, research and policy making in the context of the Olympic Games as an educational project. It is contended that the official evaluations of the Inspire programme failed to provide answers to the key questions of why, how and under what conditions the programme effects have occurred and for whom. In this way they further perpetuate the mythical powers of the Olympics to change young people's behaviour through sport on the basis of highly problematic evidence.

\section{Keywords}

Evidence, inspiration, London 2012, Olympic Games, programme, realist evaluation, young people

\section{Introduction}

The notion of inspiration is central to Olympism. Olympic discourses abound with references to personalities, events, ancient and modern symbols and stories that have been variously evoked as a source of inspiration. For the first time in history the organisers of the 2012 London Olympic and Paralympic 
Games have endeavoured explicitly to use the Games to inspire a generation and to change young people's way of life. This vision of change is a direct reference to a key intellectual figure of the ancient Olympic world, Pythagoras, who was credited to have the charisma to 'inspire a way of life' (Spivey, 2011: 35). The goal of the London Organising Committee of the Olympic and Paralympic Games (LOCOG) was 'to host an inspirational, safe and inclusive Olympic and Paralympic Games and leave sustainable legacy for London and the UK' (Girginov, 2012: 135). This is nothing short of putting the main claim of Olympism to the test, but surprisingly, so far, the Inspire project has received virtually no scholarly scrutiny. This lack of attention to a fundamental Olympic claim is echoed by Sugden and Tomlinson (2012: 264-265), who observe that 'much work on the Olympics has concentrated on the Olympics as product and event, rather than the process of meaning-making underlying the getting and staging of the Games'. A closer scrutiny of the Inspire project also allows addressing a wider issue about the relationship between evidence, research and policy making in the context of the Olympic Games.

This paper interrogates the London 2012 Inspire programme from a realist evaluation perspective (Pawson, 2013) and addresses the question: what are the theory, mechanisms and out-comes of the programme? It is structured in three parts: first, the Inspire programme is analysed in light of the relationship between evidence and claims about the powers of the Games; second, the realist evaluation perspective is presented with the view to provide a framework for examining the Inspire programme; and finally, both the Inspire and the International Inspiration Programme are discussed. The study carries conceptual and practical implications in that it helps to better understand the design and implementation of Games-related educational policies and programmes.

\section{London 2012 Inspire programme: rationale, evolution and claims}

Studies on the inspirational effect of sporting events are virtually non-existent. In the context of the Olympic Games, the notion of inspiration encompasses a number of social, political and economic discourses, policies and interventions where elite athletes play a limited role. Payne et al.'s (2003) literature review concludes that there is very little academic or industry-based evidence to support the anecdotally proposed causal link between role models and sports participation. The lack of realistic role models is noted by Allender et al. (2006), while Mutter and Pawlowski (2014) report only a modest positive influence of professional footballers on participation. Yet public agencies keep perpetuating the belief in the inherent good of sport that 'provides inspirational role models who can engender community pride and help strengthen the social fabric of divided communities, regions or countries' (Australian Sport Commission, 2009: 
117).

Olympic inspiration can be seen as part of a broader reorientation of the Olympic Movement's priorities from being concerned with delivering the Games as a project, to making real changes in society as a result of staging them (Girginov and Hills, 2008; IOC, 2015). London organisers have explicitly linked the Games with inspiration on a mass scale so any outcomes and impacts could be attributed to the deliberate actions of various actors rather than just happening by chance. The role of the Games in social development is an age old issue which was at the heart of Gilbert West's (1749) Dissertation on the Olympick Games, the first modern history of the Ancient Olympic Games. West was concerned with the quality and sufficiency of evidence and analysis used in the study of society. He posed questions that are fundamental for scientific inquiry as we know it today and wondered how it is possible to understand attitudes and events accurately when the material available for studying the ancient games was so often myth, fable and tradition.

Defining inspiration is a challenging task as it has been discussed mainly in art, literary studies and theology (Sawyer, 1999), and there is plenty of anecdotal evidence about inspira-tional leaders in management literature (Mintzberg, 2011). From an educational point of view, as Phenix (1963: 3) explains:

inspiration is the giving of spirit, and an inspired person is one who is free, creative, decisive, conscious of his proper goals, and motivated to pursue them effectively. He is fully alive, integrated, and active in the realization of his purposes. He acts deliberately and not routinely or compulsively.

Since at its core Olympism is an educational project can we expect the Games to evoke similar creativity, decisiveness and deliberate actions on the part of young people?

Operationalising inspiration is not a lesser challenge either. For example, the vision of the International Paralympic Committee (IPC) is 'to enable Paralympic athletes to achieve sporting excellence and to inspire and excite the world' where to inspire means, 'to touch the heart of all people for a more equitable society' (IPC, 2014). The goal of the 2016 Rio Olympic organisers is 'the union of all Brazilians ... ' (SAGE, 2014: 15) where inspiration is evoked to play the role of a nationally unifying force despite social, cultural and political divides. London 2012's vision of hosting an inspirational Games suggests a more micro level focus where everybody is invited to imagine their own inspiration.

The inspirational ambitions of the London 2012 Games organisers have evolved over time, and it is important to understand how they came about and assumed the central role that has been afforded to them. McNeill (2006) suggests a two-step guide for unpacking the framing of meaning of inspiration where it is interpreted first as how attention was drawn to the issue of 
inspiration, and second, determining how this idea was viewed and taken up in the UK. The London Olympic bid document associates inspiration with two classic symbols - the iconic sport venues ('Such celebrated locations as Hyde Park and state of the art venues such as the new Wembley Stadium will inspire competitors to achieve personal bests') and role models and heroes ('figures who demonstrate principled behaviour and high achievement inspire the nation') (British Olympic Association (BOA), 2005: 2).

These two principal extrinsic sources of inspiration were gradually replaced by the Government with a more politically focused approach: 'Our mission for 2012 is to inspire people to get involved and to change the way they live their lives' (Department of Media, Culture and Sport (DCMS), 2007: 1). The Government's commitment has given inspiration a particular impetus and elevated its place on the agenda of various agencies. As McFee (2012: 39) points out, London's Olympic ambitions represented a catalogue of extrinsic values (i.e. getting people more active, elite success) and 'show that governments typically regard Olympism's promise in extrinsic terms, despite claims to the contrary'. Intrinsic values of sport rooted in individual persons' learning and understanding (i.e. about 'the love of sport' (McFee (2012)) infused through education were largely relegated.

It was only natural for the inspiration to be operationalised and given specific meanings. In 2008 LOCOG launched a 'new Olympic first' in the form of an 'Inspire Mark' and in 2012 'Inspire a Generation' became the Games official motto. Inspire is a UK-wide programme, the broader objective of which is to promote non-commercial projects 'that have been inspired by London 2012 and have created opportunities for millions of people to feel part of the Games and get involved in activity spanning sport, education, culture, volunteering, business and sustainability' and 'as an acknowledgment of their excellence ....' (LOCOG, 2008). The chief mechanism for implementing the Inspire programme was a series of local and national programmes. Inspire was also charged with the task of delivering a diverse range of outcomes in four main areas (Table 1).

Although the Candidature file contains no specific reference to the role of the Games in international development, the London 2012 bid team subsequently made a commitment to reach young people all around the world and connect them to the inspirational power of the Games so they are inspired to choose sport. As a result, UK Sport, LOCOG, and a range of other agencies (e.g. British Council, UNICEF) launched an International Inspiration programme aimed at reaching 12 million children in 20 countries by 2014 when the programme was terminated. A budget of $£ 40$ million was provided mainly by the DCMS and the Department for International Development. 
Table 1. Inspire programme key outcomes.

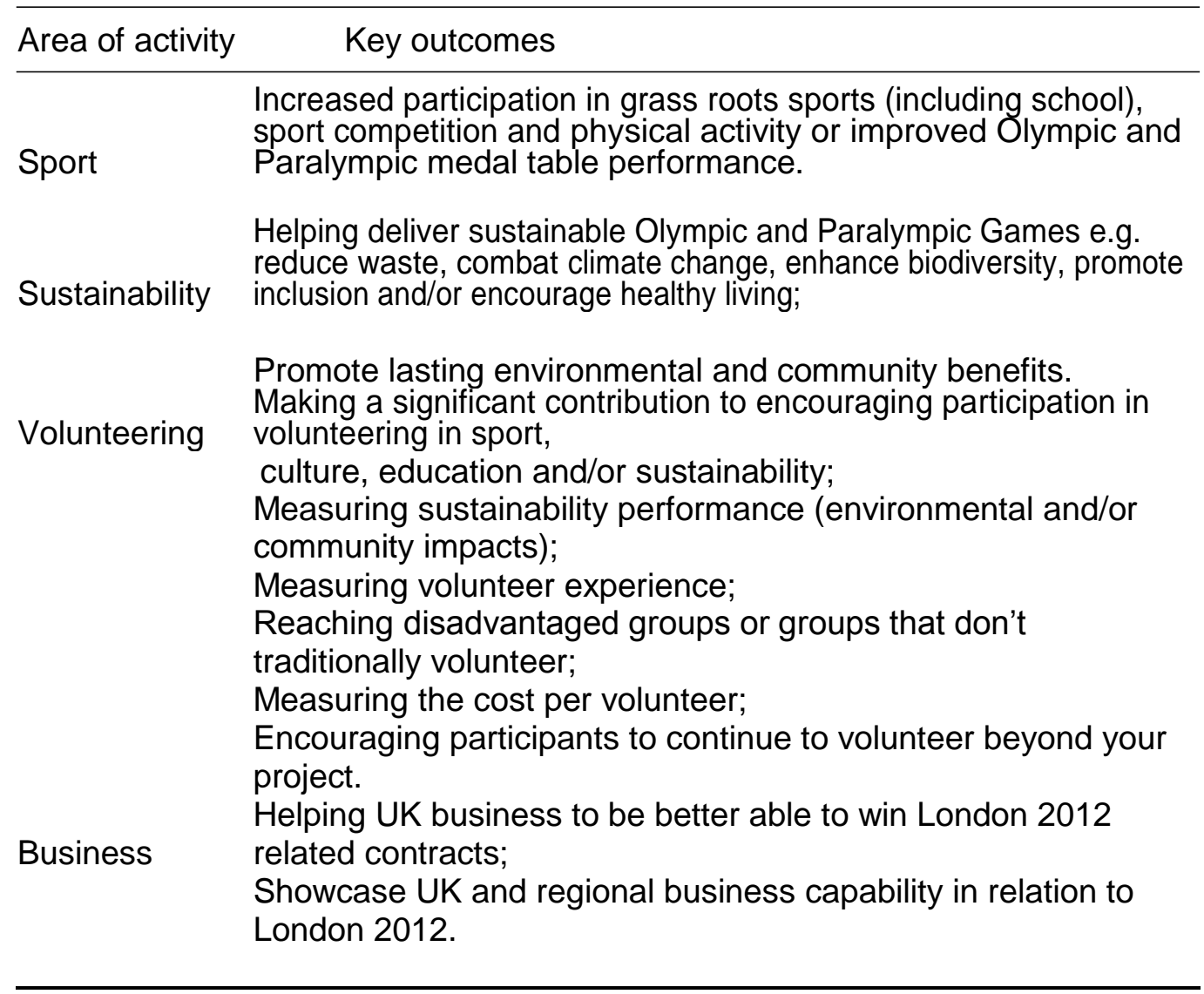

Source: LOCOG (2011).

McNeill's (2006) second step in understanding how Olympic inspiration was viewed and taken up in the UK reveals that it took three years to establish the programme after London was awarded the Games. As Garcia (2012: 27-28) explains:

The Inspire programme . . w was defined as a 'licensing programme' and it was originally conceived within LOCOG's Culture, Education and Ceremonies Team with a focus on providing a mechanism for the involvement of cultural organisations to deliver cultural and arts activities. However, once the mark was approved by the IOC as non-conflicting with their commercial branding regulations, it was used as a mechanism for Games associations across a wider diversity of sectors.

The programme was discontinued in December 2011 and, in total, 2713 
projects were awarded the Inspire Mark. The home country spread of projects was 3\% in Northern Ireland, 4\% in Wales, 3\% in Scotland and 90\% in England, of which $15 \%$ were in London (Table 2).

LOCOG/Nielsen (2012) claims that over 10 million (1 in 6) people in the UK have been involved in Inspire projects, and that at least 20 million opportunities to get involved in the Games were created. Sport projects both nationally and locally formed the bulk of the programme, while the share of educational, business and sustainability projects was surprisingly low. Furthermore, discontinuing the programme seven months prior to the start of the Games has effectively denied many projects the opportunity to draw from the very extrinsic sources of inspiration on which the Olympic promise was based.

In sum, the Inspire programme represents a manifest response to a priority social need 'to inspire a generation' and was created by a political decision of the UK Government and LOCOG, which was endorsed by the IOC. The programme was premised on several key assumptions: first, the Games bring about certain benefits which are to be shared by everybody provided that individuals and groups take part (i.e. necessary condition); second, Inspire is a mechanism for connecting young people with the Games by creating the opportunities for participation (i.e. universal connector); third, it opens up new choices for people, which were not previously available (i.e. enabler); fourth, it is a signifier of excellence across a range of human endeavours ranging from sport, to culture, education, business and the environment (i.e. Olympic inspiration is universal); and finally, it is a bridge between the elitist character of Olympic competition, which is the domain of a selected few, and the egalitarian appeal of Olympism aimed at humanity in general. These assumptions of the Inspire programme will be examined through a realist evaluation lens which is presented next.

Table 2. Distribution of Inspire projects across the six categories.

\begin{tabular}{lcc}
\hline Inspire project category & $\begin{array}{c}\text { Local/regional projects (\%) } \\
\text { Total: } 2713\end{array}$ & UK wide projects (\%) \\
& & Total: 76 \\
\hline Business & 3 & 1 \\
Education & 17 & 30 \\
Sport & 43 & 34 \\
Sustainability & 4 & 7 \\
Volunteering & 7 & 11 \\
Culture & 26 & 16 \\
\hline
\end{tabular}

Source: LOCOG/Nielsen (2012). 


\section{A realist evaluation perspective}

Realist evaluation is a relatively new workday research strategy, but realism, as a form of scientific explanation on which it is based, has a long intellectual history. It is beyond the scope of this paper to offer a comprehensive account of the realist evaluation as its ontology, epistemology and practices have been extensively discussed by others including in sport (Bhaskar, 1978; Coalter, 2013; Francis and Jenkins, 2013; Henry et al., 1998; Hughes, 2013; Patton, 2011; Weiss, 2000). It is important, however, to recognise the political inherency of all programme evaluations (Patton, 1987) including the realist perspective.

At the heart of realist evaluation, as Pawson (2013: 2) asserts, is the effort 'to remain faithful to the key tenets from the philosophical page and to apply them in the practical struggle to make sense of the policy melee'. Its first premise is that it is a theory-driven form of evaluation based on the 'if-then' proposition. Pawson explains (2013: 87): 'the preliminary idea, ambitions, expectation, hypothesis or "programme theory" is that if certain resources (sometimes material, sometimes social, and sometimes cognitive) are provided then they will initiate subjects' reasoning, generating a change in collective behaviour'.

A second premise of realist evaluation is its focus on explanation under the slogan 'what works for whom, in what circumstances and why'. A key assumption of the realist explanation is that 'interventions do not work, it is the interpretations of their subjects that produce results' (Pawson, 2013: 34). In other words, programme subjects are active agents who do not simply respond to interventions as a ship to waves, rather they actively interpret the messages of the programme, its offerings and assess the costs and benefits before committing to participation. The next property of realist evaluation is the programme theory (not so much the programme per se) as a main unit of analysis. A programme is a complex social intervention introduced into a complex social system, and is made up of inputs, outputs, outcomes, impacts and context. A thorough understanding of the workings of a programme ought to examine all these elements and their relationships. Pre-supposing patterns is another key property of realist evaluation. As Pawson (2013: 21) expresses, 'realist evaluation works by explaining outcome patterns and these cannot be determined through anecdotal remarks (on the part of the subjects) or wishful thinking (on the part of evaluators)'. A further property concerns the configuration between context, mechanism and outcome (CMO), which is a hypothesis suggesting that programmes work (Outcome) because of some underlying mechanisms (Mechanism), which is activated in a particular context (Context). Thus, realist evaluation seeks to examine these complex configurations rather than producing a catalogue of factors involved in a programme.

The next property of realist evaluation concerns complexity, which permeates this form of inquiry. Programme complexity is caused by a combination of 
factors including the number of interacting components, diverse behaviours and group/organisations to be addressed, possible outcomes and the degree of flexibility required. In short, complex interventions are those which are marked, among others, by multiplicity of sites (i.e. individuals, interpersonal relations, institutional settings, infrastructure), ambitions, stakeholders, forms of participation, funding and reporting mechanisms.

Finally, a key assumption of the realist evaluation is Rossi's iron law, which suggests that 'the expected value of any net impact assessment of a large scale social programme is zero' (Pawson, 2013: 12). This law is a natural consequence of the second property of realist evaluation elaborated above, as indeed if a programme has ill-defined objectives and is delivered by poorly qualified agencies it would be unlikely to produce any meaningful impacts. The Inspire programme was introduced in 2008 on top of 12 existing national and a myriad of local Olympic programmes (DCMS, 2013: 10). From a realist perspective, it was presented as a connector, enabler and sig-nifier, but we know virtually nothing about its inputs and contexts, and there is very limited evidence of its outputs and impacts.

\section{Method}

A sequential exploratory research design (Robson, 2011) was adopted, the primary focus of which was to explore the phenomena of Olympic inspiration. This is a two-phase process where the initial qualitative data collection was followed by a phase of quantitative data collection and analysis. Thus, the study represents a summative form of evaluation of the Inspire programme by examining its proclaimed outcomes, but its findings also bear formative implications for future programmes.

\section{Data collection}

Qualitative and quantitative methods of data collection were employed. First, notes were taken during the process of personal communications with LOCOG's Inspire unit over the application, approval, delivery and evaluation of two Inspire projects in 2011 and 2012. This was com-plemented with personal communications and note taking with the leaders of 10 Inspire projects in England. Second, two sets of documents were collected including the Inspire application form, information pack and guidelines and the three governmentsponsored official evaluations of the Inspire project (France and Jenkins, 2013; Knight et al., 2013; LOCOG/Nielsen, 2012). These two sets of data also served as a form of triangulation as they allowed comparing official documents with personal experiences and primary data. 


\section{Data analysis}

Data analysis was theory-driven as it has sought to address the main research question of what are the theory, mechanisms and outcomes of the programme. First the tracking method was used, which suggests that the actions of persons/organisations leave tracks in records and documents (Caulley, 1983). Here, the focus of analysis was on what was done by organisations and their members, how and why it was done in framing the meaning of inspiration and its delivery and outcomes. The second method was document analysis, which ' . . . is a process of evaluating documents in such a way that empirical knowledge is produced and understanding is developed' (Bowen, 2009: 33-34). It involved superficial and thorough examination and interpretation of the texts. This iterative process combines elements of content analysis and thematic analysis. The analytic procedure used four analytic codes (i.e. framing, programme theory, mechanism and outcome) and entailed finding, selecting and appraising documents and notes. Content analysis helped organise the information into the four categories related to the central question of this research. For example, unpacking the Inspire programme theory has allowed the research to identify the presumed causal relationship between interventions and participants' behaviour, the level of incentive offered and interactions.

\section{Results and discussion}

The official evaluations of both the Inspire Mark (Knight et al., 2013; LOCOG/Nielsen, 2012) and the international Inspiration programme (France and Jenkins, 2013), albeit very different in depth and breadth, paint an overwhelmingly positive picture of success and further reinforce the unshakable belief in the transformative powers of the Olympics. As Pawson (2012: 71) observes 'the science of evaluation starts by recognising that the fate of social policy lies in the real choices of choice makers and its task is to explain the distribution and consequences of those choices rather than to condemn them'. A reference to West's (1749) main contribution to knowledge is unavoidable here. He submitted that the Ancient Olympic Games were essentially a political institution that was grounded in great political views designed to model docile citizens. West entitled the final chapter (XVII) of his dissertation 'Of the utility of the Olympic Games' where he specifically emphasised the politically unifying role of the Olympics and their contribution to the moral and physical training of the youth in the service of the federal state of Greece. Therefore, in line with evaluations' political inherency, the official Inspire reports reassert the 'if-then' pro-position in that the Games provided a range of social, material and cognitive resources, which resulted in creating numerous opportunities for people to get connected with the Olympics. 


\section{Framing the programme}

Olympic inspiration was framed over time through a combination of political (DCMS, 2007, 2008), organisational (LOCOG, 2008) and popular discourses (e.g. media). The Inspire pro-gramme has sought to frame a number of important meanings designed to shape the character of various groups and organisations. Two parallel inspirational discourses were created promoting 'loud (i.e. highly visible and exclusive) and silent (low key and inclusive) places of history' pertinent to Olympic sponsors and various local groups respectively (Girginov, 2013: 6). This further reinforced the divide between elitism (i.e. fair) and egalitarianism (i.e. temple (Martinkova, 2012)) inherited in Olympism. It is worth noting that 'loud' discourses and practices promoted by LOCOG benefited from an unprecedented bracketing from their environment in the form of bespoke legislation, tax exemptions, exclusion zones and governmental financial and security guarantees (Girginov and Olsen, 2013), but no Inspire project was afforded similar support.

Since the Olympic Games represent the highest forum of athletic excellence, by extension, the Inspire Mark has also assumed the role of a signifier of excellence but on a much wider scale. Official discourses have made it hard for young people and various organisations to dismiss the sense of communitas (Turner, 1969) generated by hosting the Olympics without pledging to do something in this regard. However, designating excellence to a mark which has no history, and which is based on prescriptive and legally binding guidelines rather than virtues, raises ontological issues and under-mines the main premise of the Inspire programme as a connector between Olympic values and young people. It also raises concerns about encouraging individuals and groups to present themselves as part of the Olympic Movement without any real effort to engage with and sustain the systematic work required to nurture Olympic values. A UK-wide survey with pupils and students (aged 7-19) reveals that when shown a list of words and phrases including the Olympic values and asked which came to mind when thinking about the Games, 'competition' was the word which most came to mind followed by 'skills', neither of which were Olympic or Paralympic values. Furthermore, the Inspire Mark was recognised only by $7 \%$ of primary and $9 \%$ secondary school children and $22 \%$ of FE college students (Bunt et al., 2011). None of the 10 Inspire Mark awarded projects observed in 2011- 2012 exists today. The only substantive remaining 'inspire' branded initiative designed specifically to carry on the spirit of the London Games is the BBC 'Get Inspired' (www.bbc.co.uk/GetInspired). This shows that without a sustained institutional commitment Games-induced inspiration can be short-lived. It also suggests that importing the same programme across very different contexts is hugely problematic and does not necessarily lead to the desired results. As Weed et al. (2015: 220) argue 'evidence from London 2012, 
however, appear to confirm that there is no inherent demonstration effect on sport participation'.

\section{Inspire programme theory}

The Inspire programme represents a complex intervention with multiple strands including multiple locations, stakeholders, objectives and delivery agencies, which was inserted into complex social and economic landscapes nationally and internationally. From a realist evaluation perspective the programme theory of Olympism, on which the Inspire was premised, could be summarised as follows: if people play value-based sport by certain rules and aspire to achieve their best (i.e. make use of the provision of material, social and cognitive resources) by respecting each other they would become better citizens and as a result the world would be a better place. Embedded in the programme were its salience through the slogan 'everyone's Games' (Coe, 2012), and the pro-motion of social norms suggesting that this is a once in a lifetime opportunity to change young people's lives, which should not be missed (DCMS, 2007).

There were, however, two rather different programme theories behind the UK and International Inspiration initiatives. The Inspire programme's ambition was that by providing a combination of social (i.e. interaction opportunities) and cognitive (i.e. information) resources it will connect people with the Games, and thus will initiate subjects' reasoning, which will lead to generating a change in collective behaviour (LOCOG, 2008). The idea of the International Inspiration was that by offering a combination of material (i.e. facilities and funding), social and cognitive resources in the form of high-quality and inclusive physical education, sport and play, it will initiate the reasoning of policy makers, practitioners and participants and, as a result, will enrich the lives of 12 million children of all abilities in schools and communities in 20 countries (France and Jenkins, 2013). Therefore, the focus of both programmes was different: Inspire targeted the everyday participant, while the International Inspiration operated at three levels - policy makers, practitioners and participants - thus adding extra layers of context. There is a considerable degree of vagueness in both theories as neither 'opportunities' nor 'enrichment of life' were clearly articulated, which leaves them open to various interpretations and makes any objective measurement highly problematic.

The analysis of the theory behind the Inspire initiatives suggests that it has generally failed to explain why, how, and under what conditions the programme effects have occurred, to predict the outcomes of the programme, and to specify the requirements necessary to bring about the desired programme effects. As Coalter (2013: 45) argues, from a realist point of view:

rarely if ever is the same programme equally effective in all circumstances because of the influence of contextual factors (which includes the 
frequently ignored issue of the nature of participants). Consequently, attempts to illustrate 'success' may need to adopt rather different approaches.

The official evaluations do not tell us who those 10 million participants were in 2713 Inspire projects across the UK nor do they talk about what requirements were met in delivering the pro-claimed programme effects, and what exactly those 20 million created opportunities mean. The UK Government's own framework for evaluating impacts of the London Games suggests that 'any outputs and outcomes that cannot be traced back through a theory of change to specific legacy strategies should not be attributed as legacies of the London 2012 Olympic and Paralympic Games' (Weed, 2013: 282) illustrates the failure of the Inspire theory of change.

The language used by LOCOG and DCMS in Inspire and other documents is also symptomatic of a typical programme assumption that 'we' (in-group) can change the behaviour of 'them' (out-group). 'We invite you to change your lives . . . ' expresses Tessa Jowell, the Olympic Minister (DCMS, 2007: 2). Knight et al.'s (2013) evaluation supports the 'we-them' distinction and reveals that the most informed and motivated people were those who initiated an Inspire project.

The link between 'we-them' and the Games deserves further analysis. Invariably, Games organisers have been using the Games to reveal the poor performance of some outgroups (e.g. physically inactive, anti-social behaviour, lack of voluntarism or educational attainments, unemployment), so the resources and public mobilisation generated in the course of the Olympics can be used to arrest it. This is a core assumption of programme theory, which presupposes that 'if the inner group reveals publically on official record of the poor or deviant performance of some outgroup, then the glare of publicity will shift their behaviour to in-group norms' (Pawson, 2013: 96). LOCOG used the Inspire Mark to intervene in the choice presented by the government in order to change people's orientation from non-members to sport and Olympic empathisers and members. However, as Merton (1968: 344-345) explains from a reference group theory point of view, the aspirants to group membership can be divided into two significantly different kinds:

the eligible aspirant for membership - who has been identified as the 'candidate' for membership - is motivated to select the non-membership group as his reference group and apt to be rewarded by the group for doing so. The ineligible aspirant, however, engaging in this anticipatory socialisation becomes a marginal man, apt to be rejected by his membership group for repudiating its values and unable to find acceptance by the group which he seeks to enter.

There is sufficient evidence for the dilemma faced by the 'ineligible aspirants', 
most of whom were the very young people of East London and elsewhere, whose lives the Games were supposed to change and who have found it hard to associate with them (Johnson et al., 2008; Sinclair, 2012). The difference in membership attitudes is underpinned mainly by the structurally defined position of the people concerned. It is worth noting that various inspirational activities were supposed to take place against a background of harsh economic conditions coupled with unprecedented cuts in public funding and a record high youth unemployment figure of 1,027,000 (ONS, 2011). Gratton and Kokolakakis (2012) found a positive statistical correlation between worsening economic conditions and declining participation in sport in the UK.

\section{Programme mechanisms}

Programme mechanisms are agents of change. As Pawson (2013: 115) explains: 'they describe how the resources embedded in a programme influence the reasoning and ultimately the behaviour of programme subjects'. The analysis therefore, becomes concerned with 'what is it about the Inspire programme that works for whom, in what circumstances, in what respects and over which duration?' Neither report provides answers to these questions. LOCOG's approach to the Inspire Mark could be described as a self-fulfilling prophecy. The Inspire application form asked projects that have been running as well as those about to start to provide demonstrable proof that they were:

(i) genuinely inspired by the London 2012 Olympic and Paralympic Games; (ii) well planned and managed; (iii) fully funded from non-commercial sources and with no commercial association; (iv) innovative and inspiring; and (v) likely to achieve at least one of LOCOG's key outcomes (LOCOG, 2011). However, in the absence of well-defined and measurable indicators neither type of project would have produced a realistic picture of the role of specific mechanisms in producing certain outcomes. No information was collected about participants (i.e. gender, educational background, abilities, and level of involvement in the programme), programme duration or the specific circumstances in which it was delivered.

The methodology for data collection in both evaluations (i.e. online and paper surveys, tele-phone conversations and face to face consultations with delivery agencies) does not allow for an explanation of the CMO of realistic evaluation: what underlying mechanisms were activated in which particular context that were responsible for the reported outcomes. In Coalter's (2013) analysis the $\mathrm{CMO}$ configuration refers to 'sufficient conditions' under which the potential programme outcomes are achieved, and which are in addition to the necessary conditions concerned with the act of participation. Other qualitative but more labour intensive methodologies such as longitudinal in-depth holistic case studies, ethnography, focus groups and personal diaries would have produced much richer and more reliable explanations. A wider critical point about both 
programmes is expressed by Pawson's (2013: 88) observation that 'programme theories are immediately portable, whereas programmes are not'. This is because of the issue of complexity discussed above, or the combination of necessary and sufficient conditions, which turns the Inspire programme from one to 2713 different programmes.

Inspire's main claim is that it created 20 million opportunities for people to be connected with the Games, but what this figure really means is that the Games only provided the context for the development of (supposedly) positive experiences for various participants (Coakley, 2001;

Table 3. Relationships between participants, type of sport, opportunities provided and change sought in selected Inspire sport projects.

\begin{tabular}{|c|c|c|c|c|c|c|}
\hline $\begin{array}{l}\text { Inspire } \\
\text { project }\end{array}$ & $\begin{array}{l}\text { Type of } \\
\text { access }\end{array}$ & $\begin{array}{l}\text { Opportunities } \\
\text { provided }\end{array}$ & $\begin{array}{l}\text { Target } \\
\text { audience }\end{array}$ & $\begin{array}{l}\text { Change } \\
\text { sought }\end{array}$ & $\begin{array}{l}\text { Centrality } \\
\text { of sport }\end{array}$ & $\begin{array}{l}\text { Type of } \\
\text { sport }\end{array}$ \\
\hline $\begin{array}{l}\text { Newham All } \\
\text { Stars Sport } \\
\text { Academy } \\
\text { Going for } \\
\text { Gold }\end{array}$ & $\begin{array}{c}\text { Relatively } \\
\text { open }\end{array}$ & $\begin{array}{l}\text { Participate in } \\
\text { competitive } \\
\text { sport; meet new } \\
\text { friends } \\
\text { Participate in sport; } \\
\text { learn new activities; } \\
\text { meet other children }\end{array}$ & $\begin{array}{r}\text {; School } \\
\text { children } \\
\text { aged } \\
9-11\end{array}$ & $\begin{array}{l}\text { Attitudes, } \\
\text { skills and } \\
\text { behaviour } \\
\text { Attitudes }\end{array}$ & $\begin{array}{l}\text { Combined } \\
\text { recreation- } \\
\text { competitive } \\
\text { Sport-plus }\end{array}$ & $\begin{array}{l}\text { Team } \\
\text { Individual } \\
\text { pairs }\end{array}$ \\
\hline $\begin{array}{l}\text { Getting } \\
\text { Ready } \\
\text { for the } \\
\text { Games }\end{array}$ & Open & $\begin{array}{l}\text { Participate in sport } \\
\text { and } \\
\text { capacity building }\end{array}$ & $\begin{array}{l}\text { Young } \\
\text { people }\end{array}$ & Attitudes & $\begin{array}{l}\text { Sport-plus/ } \\
\text { Plus-sport }\end{array}$ & $\begin{array}{l}\text { Individual } \\
/ \\
\text { t Team }\end{array}$ \\
\hline V-Inspired & $\begin{array}{l}\text { Outreach } \\
\text { youth } \\
\text { work }\end{array}$ & $\begin{array}{l}\text { Opportunities for } \\
\text { young } \\
\text { people to do good } \\
\text { things }\end{array}$ & $\begin{array}{l}\text { Young } \\
\text { people } \\
\text { aged } \\
14-25\end{array}$ & $\begin{array}{l}\text { Attitudes } \\
\text { and } \\
\text { behaviour }\end{array}$ & Plus-sport & Team \\
\hline
\end{tabular}

MacAloon, 2008). However, far more important is the social process of participation, which is facilitated by important mechanisms such as knowledgeable instructors, friendly staff and participants or easy access, but none of the evaluation reports delves into this issue (Rowe et al., 2004). Research shows that successful sport programmes work through strong respect, trust and reciprocity by creating relationships and trust between providers and participants (Coalter, 2013). LOCOG had neither the remit nor the capacity to establish such relationships with millions of participants. Its raison 
d'etre was to deliver the Games as a project.

To further illustrate the above issues, four Inspire sport projects are briefly analysed above (Table 3). Following a lead from Coalter (2013) the centrality of sport in each project is considered. This is because sport may play a relative role including: (i) combining recreational and competitive activities; (ii) sportplus, in which sport represents a context for changing values; and (iii) plussport, in which free access to sport is used to reward young people where sport provides the context for intensive youth work practice. Participants' recruitment is another key mechanism, which can vary along the lines of: (i) open access (based on a deficit model that all young people from a designated area will have the same negative propensities); (ii) relatively open access (a targeted outreach approach); and (iii) versions of outreach youth work (befriending young people in a sporting context in order to conduct further youth work).

As Table 3 shows, each of the four Inspire projects has been variously constructed, which has resulted in a range of socialising experiences and outcomes. The projects' duration varies from one-off day of sport (Going for Gold) to an established programme for multiple age groups (NASSA) and presupposes different levels of trust, reciprocity and relationship: for the 9-11 year old children of West London this was a nice day out in a new environment, whereas for the troubled young people of Newham in East London, participation was part of a long-term commitment where they needed to form a trustful relationship with coaches, volunteers and academy management. All four projects were based on a deficiency approach and aimed to address poor or deviant performance of some outgroup (e.g. antisocial behaviour and exclusion - NASSA, and low participation/membership in volleyball - V-Inspired). Thus, the opportunities provided for connecting with the Games have taken a very different form and meaning in each context, which do not automatically associate them with what the Olympics stand for. What is more, the inspiration generated by major sporting events is neither equal nor unequivocal across various participants and sports. Three of the four programmes offer open access to (self-selected) participants who may or may not be associated with the issues the programme seeks to address. As Coalter (2013: 150) warns, such open access programmes 'will have an inconsistent and probably weak impact on values, attitudes and aspirations, as participation will only be one of a range of, often more influential activities and experiences'.

Ramchandani and Coleman (2012) demonstrate that the inspirational effect of sporting events on participation is much more pronounced in the younger age group (16-34) compared to the other two groups of participants (35-54 and $55 p)$. Another important finding of their study concerns the 'ineligible participants' (i.e. out-group) and how they engage with the opportunities provided by the Games where less physically active people are less likely to be inspired and to become a member of the 'in-group'. Results about the 
inspirational effects of the 2016 Rio Games suggest that between 2009 and 2011 , the proportion of physically active people both in the host state and Brazil in general has declined from $18 \%$ to $12-14 \%$ (SAGE, 2014: 139). Similarly, participation figures in England fell after London 2012 (Sport England, 2015), which seem to challenge the perceived ability of the Olympics to inspire participation.

\section{Programme outcomes}

It remains unclear what exactly the Inspire programme wanted to change people's attitudes, beliefs or behaviours. If judged by its stated outcomes (Table 1), it becomes apparent that the inspirational connection with the Games was charged with introducing change in a very broad range of personal and collective behaviours regardless of context and type of participants. This is a very problematic assumption because, as Pawson (2013: 92) warns, 'programmes do not just incentivise, they select behaviours thought to respond to incentives, they choose subjects, they pick incentive levels thought to shift behaviour, and so on'. In this regard the International Inspiration was far more focused on selected school children and young people, as well as their leaders and policy makers and offered to 'connect them to the inspirational power of the Games so they are inspired to choose sport' (LOCOG, 2007: 2). The incentive levels were also more clearly defined - to introduce new policies and legislation, and to provide resources and quality experiences. There is hardly anything original in the use of sport in international development since this is precisely why Olympic Solidarity was established in 1962. The international Inspiration is not substantially different from the myriad of contentious interventions that have been seen by many commentators as a form of neo-colonialism where the global North teaches the global South how to behave (Coalter, 2009; Darnell, 2010; Giulianotti and Robertson, 2004; Hartmann and Kwauk, 2011; Levermore, 2008). Coalter (2013) refers to similar attempts for presenting sport for development as a novel idea as 'conceptual entrepreneurism'.

The Inspire Mark lacks a programme focus as it proposes to deliver 12 outcomes (i.e. behaviour changes) across four large domains without specifying its target audience and levels of incentive. It is not surprising that LOCOG/Nielsen's (2012) evaluation found that $25 \%$ of the projects were not connected in any way to any of the 12 major national and cross field Olympicrelated programmes (e.g. Cultural Olympiad, GetSet, London 2012 Festival). Knight et al. (2013) report that $24 \%$ of participants were not aware they were taking part in an Inspire project (47.8\% were aware), a further $28.2 \%$ became aware through taking part in an 'Inspire' activity, $31.4 \%$ had not heard of it, $34.3 \%$ heard but could not describe it, and $34.2 \%$ heard about and could describe it. Weed (2014) also questioned the high number of genuinely inspired projects. These findings put into question the effectiveness of the two key 
programme resources - information (i.e. lack of communication with target groups) and interaction (i.e. unclear motivation of participants).

\section{Conclusion}

The UK and the International Inspiration programmes were based on two different theories of change grounded in the fundamental premise of Olympism that sport is a tool for moral education, but neither was explicitly formulated. Coakley and Souza (2013) challenge the inherent mythical powers of sport, and mega events in particular, to bring about exclusively positive social and economic benefits and expose the flaws of the logic behind the lack of credible evidence.

The Inspire programme partly defies this logic in that it was subjected to formal evaluations although the actual interventions were neither prioritised nor carefully planned and implemented. Rather, they bear the signs of ad hoc activities that were introduced on top of various other existing programmes within complex socio-political environments. Official evaluations provide no answer to the question of how the social, material and cognitive resources, embedded in the Inspire programme, have impacted on its subjects' reasoning and behaviour. Both projects were considerably vague in their definitions of the purported major outcomes of 'opportunities' and 'enrichment of life', which leaves them open to various interpretations and eventually made their objective measurement highly problematic. The explicit assumption behind the requirement to demonstrate that projects were genuinely inspired by the Games is that it is possible to develop a universal programme of social change that is almost completely divorced from any context and history of participants. Existing evaluations do not tell us what inspiration meant for participants and how it was turned into successful patterns of mechanisms.

The relationship between the source and the inspired person is a contentious one. The Olympic Charter defines Olympism as a 'philosophy of life' and from the perspective of modern Western philosophy, Olympism aims at articulating a single universal truth. Reid and Evangeliou (2010) demonstrate that this is not the only way of interpreting Olympism, noting that Eastern and Hellenic interpretations emphasise process and disposition as opposed to the Western pre-occupation with results and control. London organisers have employed the latter interpretation of inspiration, which emphasises project cycle and management inspired and oriented plannable change in predictable environments. This approach offers a number of management advantages, not least because it allows the use of methods for measuring results. The drive for manageability of inspiration can lead to instrumentalist practices, thus creating an illusion of control. This is exemplified in presenting London's experience to the world as 'best practice', which is the antithesis of realist evaluation. The former interpretation of inspiration, which focuses on process and disposition, 
sees social change as emerging in complex environments but its practical use is still in its infancy.

Interrogating the Inspire programme allows describing the relationship between research and Olympic policy making as akin to the policy model of evaluation (Weiss, 1979) where policy makers draw on research to justify decisions already taken. This relationship is different from the interactive or the enlightenment models where research offers considerable input and its impact on policy making is carefully considered. Two answers to the main research question 'has the London 2012 Inspire programme inspired a generation?' transpired. The political answer promoted by official agencies claim outcomes that cannot be genuinely attributed to the Inspire programme. The realist answer, offered by this analysis, suggests that the Inspire project has failed to make any meaningful contribution to our understanding of the inspirational powers of the Olympics.

While proving causality between the Olympic Games and young people's inspired behaviours is likely to confirm Rossi's (1987) iron law of evaluation that the net impact assessment of a large scale social programme is zero, it is worth pursuing a greater complementarity between the Olympic appeal and wellconceived and implemented policy interventions and evaluations.

\section{References}

Allender S, Cowburn G and Foster C (2006) Understanding participation in sport and physical activity among children and adults: a review of qualitative studies. Health Education Research 21(6): 826-835.

Australian Sport Commission (2009) The future of sport report (Crawford Report). Canberra: ASC. Bhaskar R (1978) A Realist Theory of Science. London: Verso.

Bowen G (2009) Document analysis as a qualitative research method. Qualitative Research Journal 9(2): 27-40.

British Olympic Association (BOA) (2005) London 2012: Response to the questionnaire for cities applying to become candidate cities to host the Games of the XXX Olympiad and the Paralympic Games in 2012. London: BOA.

Bunt K, Llewellyn-Thomas S, Campbell-Hall V, et al. (2011) Schools' and Colleges' Engagement with the 2012 Olympic and Paralympic Games: PE and Sport. London: Department of Education.

Caulley D (1983) Document analysis in programme evaluation. Evaluation and Program Planning, 6: 19-29. Coakley J (2001) Sport in Society - Issues and Controversies. 7th ed. Boston: McGraw-Hill.

Coakley J and Souza D (2013) Sport mega-events: can legacies and development be equitable and sustain-able? Motriz, Rio Claro 19(3): 580589. 
Coalter F (2009) Sport-in-development: accountability or development? In: Levermore $\mathrm{R}$ and Beakom A (eds) Sport and International Development. London: Palgrave MacMillan, pp.55-75.

Coalter F (2013) Sport for Development: What Game are we Playing? London: Routledge. Coe S (2012) Foreword. LOCOG Annual Report. London: LOCOG.

Darnell S (2010) Power, politics and sport for development and peace: investigating the utility of sport for international development. Sociology of Sport Journal 27(1): 54-75.

Department of Media, Culture and Sport (DCMS) (2007) Our Promise for 2012: How the UK will Benefit from the Olympic and Paralympic Games. London: DCMS.

Department of Media, Culture and Sport (DCMS) (2008) Before, during and after: Making the most of the London 2012 Games. London: DCMS.

Department of Media, Culture and Sport (DCMS) (2013) Report 5: Post-Games Evaluation. Meta-Evaluation of the Impacts and Legacy of the London 2012 Olympic Games and Paralympic Games: Summary Report. London: DCMS.

France J and Jenkins S (2013) Final Report Evaluation of International Inspiration. London: Ecorys. Garcia B (2012) London 2012 Cultural Olympiad Evaluation: Final Report. University of Liverpool: Liverpool. Girginov V (2012) Governance of the London 2012 Olympic and Paralympic Games. In: Girginov V (ed.) Handbook of the London 2012 Olympic and Paralympic Games. Volume One: Making the Games. London: Routledge, pp.130-134.

Girginov V (2013) Researching and writing about the London Olympics. In:

Girginov V (ed.) Handbook of the London 2012 Olypmic and Paralympic Games. Volume Two: Celebrating the Games. London: Rou-tledge, pp.1-17.

Girginov V and Hills L (2008) A sustainable sports legacy: creating a link between the London Olympics and sports participation. The International Journal of the History of Sport 25(14): 2091-2117.

Girginov V and Olsen N (2013) LOCOG: a temporary organisation within a highvelocity environment. In: Girginov V (ed.) Handbook of the London 2012 Olympic and Paralympic Games. Volume 2: Celebrat-ing the Games. Routledge: London, pp.71-83.

Gratton C and Kokolakakis T (2012) The effects of the current economic conditions on sport participation. A report. Sport Industry Research Centre, UK.

Giulianotti R and Robertson R (2004) The globalization of football: a study in the glocalization of the 'serious life'. The British Journal of Sociology 55(4): 545568.

Hartmann D and Kwauk C (2011) Sport and development: an overview, critique, and reconstruction. Journal of Sport and Social Issues 35(3): 284-305.

Henry G, Mark M and Julns G (1998) Realist evaluation: an emerging theory in support of practice. New Directions for Evaluation, 78, San Francisco: Jossey-Bass. 
Hughes K (2013) Sport mega-event and a legacy of increased sport participation: an Olympic promise or an Olympic dream? PhD Thesis, Leeds Metropolitan University, UK

IOC (2015) The Contribution of Sport to the Sustainable Development Goals and the Post-2015 Development Agenda. New York: IOC.

IPC (2014). The IPC - Who we are. Available at: http://www.paralympic.org/ThelPC/HWA/AboutUs (accessed 2 February 2014).

Johnson F, Fraser J, Ganesh G, et al. (2008) The London 2012 Olympic Games and Paralympic Games - Children and Young People's Perceptions and Involvement. London: Department for Children, Schools and Families.

Knight J, Kavanah P and Page D (2013) London 2012 Olympic Games and Paralympic Games: Inspire Pro-gramme Legacy Survey: United Kingdom. London: Kavanah, Knight and Page.

Levermore R (2008) Sport: a new engine of development? Progress in

Development Studies 8(2): 183-90. LOCOG (2007) London 2012 Annual

Update. London: LOCOG.

LOCOG (2008) On Track. Annual Report 2007-2008.

London: LOCOG. LOCOG (2011) London 2012 Inspire

Programme. London: LOCOG.

LOCOG/Nielsen (2012) Inspire Programme: Key Facts and Figures. London: LOCOG.

MacAloon J (2008) 'Legacy' as managerial/magical discourse in contemporary Olympic affairs. Interna-tional Journal of the History of Sport 25(4): 20602071.

McFee G (2012) The Promise of Olympism. In: Sugden J and Tomlinson A (eds) Watching the Olympics: Power, Politics and Representation. London: Routledge, pp.36-52.

McNeill D (2006) The diffusion of ideas in development theory and policy. Global Social Policy 6(3): 334-354. Martinkova I (2012) Fair or temple: two possibilities for Olympic sport. Sport, Ethics and Philosophy 6(2):

166-182.

Merton R (1968) Social Theory and Social Structure. New York: The Free Press. Mintzberg H (2011) Managing. New

York: FT Prentice Hall.

Mutter F and Pawlowski T (2014) Role models in sports - can success in professional sports increase the demand for amateur sport participation? Sport Management Review 17(3): 324-336.

ONS (2011) Internet Access - Households and Individuals. London: ONS. Patton M (1987) Evaluation political inherency. Practical implications for design and use. In: Palumbo DJ (ed.)

The Politics of Programme Evaluation. Newbury Park, CA: Sage, pp.100145.

Patton M (2011) Developmental Evaluation: Applying Complexity Concepts to 
Enhance Innovation and Use. New York: Continuum.

Pawson R (2013) The Science of Evaluation. London: Sage.

Payne W, Reynolds M, Brown S, et al. (2003) Sports Role Models and their

Impact on Participation in Phys-ical Activity: A Literature Review. University of

Ballarat: Ballarat.

Phenix P (1963) Educational theory and inspiration. Educational Theory 13(1):

$1-64$.

Ramchandani $G$ and Coleman R (2012) The inspirational effects of three major sport events. International Journal of Events and Festivals Management 3(3): 257-271.

Reid H and Evangeliou C (2010) The political heritage of the Olympic Games: Relevance, risks, and possible rewards. In: Proceedings: International Symposium for Olympic Research. London: University of Western Ontario.

Robson C (2011) Real World Research (3rd ed.). Chichester: Wiley.

Rossi P (1987) The iron law of evaluation and other metallic rules. In Miller JL and Lewis M (eds) Research in Social Problems and Public Policy: A Research Annual (Vol. 4) New York: Jai Press, pp.3-20.

Rowe N, Adams R and Beasley N (2004) Driving up Participation in Sport: The Social Context, the Trends, the Prospects and the Challenges. London: Sport England.

SAGE (2014) Olympic Games Impact (OGI) Study - RIO 2016 Initial Report to Measure the Impacts and the Legacy of the Rio 2016 Games: Rio de Janeiro: SAGE/COPPE/UFRJ Research Team.

Sawyer J (1999) Theories of inspiration. Available at: http://www.bible.org/docs/theology/biblio/theorins. htm (accessed 21 January 2014).

Sinclair I (2012) Ghost Milk: Calling Time on the Grand Project. London: Hamish Hamilton.

Spivey N (2011) Pythagoras and the origin of Olympic ideology. In: Girginov V (ed.) Olympic Studies, Vol. 1. Origins and Revival of the Modern Olympic Games. London: Routledge, pp.21-39.

Sport England (2015) The national picture. Active people survey results. Available at: http://www.sporteng- land.org/research/who-playssport/national-picture/ (accessed 18 June 2015).

Sugden J and Tomlinson A (2012) 'No other anything . . ' ': The Olympic Games yesterday and today. In: Sug-den $\mathrm{J}$ and Tomlinson $\mathrm{A}$ (eds) Watching the Olympics: Power, Politics and Representation. Routledge: London, pp.242251.

Turner V (1969) The Ritual Process: Structure and Anti-structure. New York:

Aldine De Gruyter.

Weed M (2013) London 2012 legacy strategy. Did it deliver? In Girginov V (ed.) Handbook of the London 2012 Olympic and Paralympic Games (Vol 2). London: Routledge, pp.281-294.

Weed M (2014) Is tourism a legitimate legacy strategy from the Olympic and 
Paralympic Games? An analysis of London 2012 legacy strategy using programme theory. Journal of Sport and Tourism 19(2): 101-126.

Weed M, Coren E, Fiore J, et al. (2015) The Olympic Games and raising sport participation: a systematic review of evidence and an integration of policy for a demonstration effect. European Sport Management Quarterly 15(2): 195226.

Weiss C (1979) The many meanings of research utilisation. Public Administration Review September/ October: 426-431.

Weiss $C$ (2000) Which links in which theories should we evaluate? In: Rogers $P$, Hacsi T, Petrosino A, et al. (eds). Program Theory in Evaluation: Challenges and Opportunities (New Directions for Evaluation, 87). San Francisco: Jossey Bass.

West G (1749) Odes of Pindar, with several other Pieces in Prose and Verse, Translated from the Greek. To which is prefixed A Dissertation on the Olympick Games. London (1749, 1753, 1766). 